\title{
Production of dengue virus envelope protein domain III-based antigens in tobacco chloroplasts using inducible and constitutive expression systems
}

\author{
Johanna Gottschamel ${ }^{1,2} \cdot$ Andreas Lössl $^{2} \cdot$ Stephanie Ruf $^{3} \cdot$ Yanliang Wang $^{1}$ • \\ Morten Skaugen ${ }^{4} \cdot$ Ralph Bock $^{3} \cdot$ Jihong Liu Clarke $^{1}$ (D)
}

Received: 13 March 2016/Accepted: 17 April 2016/Published online: 26 April 2016

(C) Springer Science+Business Media Dordrecht 2016

\begin{abstract}
Dengue fever is a disease in many parts of the tropics and subtropics and about half the world's population is at risk of infection according to the World Health Organization. Dengue is caused by any of the four related dengue virus serotypes DEN-1, $-2,-3$ and -4 , which are transmitted to people by Aedes aegypti mosquitoes. Currently there is only one vaccine $\left(\right.$ Dengvaxia $\left.^{\circledR}\right)$ available (limited to a few countries) on the market since 2015 after half a century's intensive efforts. Affordable and accessible vaccines against dengue are hence still urgently needed. The dengue envelop protein domain III (EDIII), which is capable of eliciting serotype-specific neutralizing antibodies, has become the focus for subunit vaccine development. To contribute to the development of an accessible and affordable dengue vaccine, in the current study we have used plant-based vaccine production systems to generate a dengue subunit vaccine candidate in tobacco. Chloroplast genome engineering was applied to express serotypespecific recombinant EDIII proteins in tobacco chloroplasts
\end{abstract}

Electronic supplementary material The online version of this article (doi:10.1007/s11103-016-0484-5) contains supplementary material, which is available to authorized users.

Ralph Bock

rbock@mpimp-golm.mpg.de

$\triangle$ Jihong Liu Clarke

jihong.liu-clarke@nibio.no

1 NIBIO-Norwegian Institute of Bioeconomy Research, P.O. Box 115, 1431 As, Norway

2 BOKU-University of Natural Resources and Life Sciences, Gregor-Mendel-Straße 33, 1180 Vienna, Austria

3 Max Planck Institute of Molecular Plant Physiology, Am Mühlenberg 1, 14476 Potsdam-Golm, Germany

4 Norwegian University of Life Sciences, Ås, Norway using both constitutive and ethanol-inducible expression systems. Expression of a tetravalent antigen fusion construct combining EDIII polypeptides from all four serotypes was also attempted. Transplastomic EDIIIexpressing tobacco lines were obtained and homoplasmy was verified by Southern blot analysis. Northern blot analyses showed expression of EDIII antigen-encoding genes. EDIII protein accumulation levels varied for the different recombinant EDIII proteins and the different expression systems, and reached between 0.8 and $1.6 \%$ of total cellular protein. Our study demonstrates the suitability of the chloroplast compartment as a production site for an EDIII-based vaccine candidate against dengue fever and presents a Gateway ${ }^{\circledR}$ plastid transformation vector for inducible transgene expression.

Keywords Dengue virus - Chloroplast transformation . Plant produced vaccine $\cdot$ EDIII antigen $\cdot$ Tobacco

\section{Introduction}

Dengue fever is a mosquito-transmitted viral disease that is currently spreading rapidly as the consequence of globalization, unplanned and unregulated urban development, improper water storage, unsatisfactory sanitary conditions and global warming (Chaturvedi and Nagar 2008). Aedes aegypti mosquitoes, which transmit dengue virus to people, also transmit the Zika virus that has spread to 52 countries and territories according to the World Health Organization (www.who.int). The dengue virus (DENV) occur in four closely related but antigenically and genetically distinct serotypes (DENV-1, DENV-2, DENV-3 and DENV-4; (Weaver and Vasilakis 2009)). Infection with any one serotype usually causes the mild, flu-like form of the 
disease (Dengue fever), but subsequent infection with a different serotype is associated with more life-threatening forms of the disease and potentially deadly complications (WHO, www.who.int).

Currently there is only one vaccine (Dengvaxia ${ }^{\circledR}$ ) available (limited to a few countries) on the market since 2015 after half a century's intensive efforts. Affordable and accessible vaccines against dengue are hence still urgently needed (Ghosh and Dar 2015; www.who.int). Among the currently tested vaccine candidates, Sanofi Pasteur's tetravalent dengue vaccine candidate (CYD-TDV) is the most promising one and has recently successfully completed the phase III clinical efficacy trials in Asia and Latin America (Thomas 2015). This tetravalent dengue vaccine candidate (Guy et al. 2011) is composed of four recombinant, live, attenuated monovalent chimeric yellow fever dengue vaccine strains (Guirakhoo et al. 2001) and showed an overall vaccine efficacy of $56.5 \%$ in the trail conducted in Asia (Capeding et al. 2014) and $60.8 \%$ in the Latin American trial (Villar et al. 2015).

The majority of attempts to produce a recombinant protein-based vaccine as an alternative to the live, attenuated vaccine candidates, focus on the envelop protein of the virus. The envelop protein domain III (EDIII) induces serotype-specific antibodies. Although it has low intrinsic potential for eliciting cross-reactive antibodies against heterologous serotypes (Hombach et al. 2005), it has emerged as the most promising region for subunit vaccine development (Guzman et al. 2010). Recombinant antigens based on EDIII have been produced using bacteria, yeast, insect cells and plants (Batra et al. 2010b; Cardoso et al. 2013; Clements et al. 2010; Etemad et al. 2008; Martinez et al. 2010; Saejung et al. 2007). Importantly, a recombinant fusion protein linking the EDIII domain of the four dengue viruses as a tetravalent antigen (EDIII-1-4) was able to elicit neutralizing antibodies against all four serotypes (Batra et al. 2007; Etemad et al. 2008).

The primary occurrence of dengue fever in low-income countries makes the need for a cost-effective vaccine production platform obvious. Advances in genetic engineering and molecular biology during the last three decades have extended the utilization of plants well beyond the traditional application as food and feed source. Although most of the available recombinant protein drugs are currently still produced in bacteria, yeast, mammalian or insect cells, rapid progress in plant biotechnology offers the prospect of converting plants into inexpensive factories for diagnostic reagents, pharmaceutical proteins and industrial enzymes within the foreseeable future (Ma and Wang 2012; Melnik and Stöger 2013).

Chloroplast transformation has emerged as a high-precision genetic engineering technique for both basic research and plant biotechnology applications with several advantages over nuclear transformation (Bock 2015; Clarke and Daniell 2011; Maliga and Bock 2011; De Marchis et al. 2016). The site-specific integration of transgenes into the plastid genome and the absence of epigenetic gene silencing mechanisms avoid position effects and gene silencing (Daniell 2006). Maternal inheritance of chloroplasts in most plant species prevents the transgene spread via pollen (Ruf et al. 2007; Svab and Maliga 2007) and the presence of up to 10,000 copies of plastid DNA in photosynthetic cells (Bendich 1987) is beneficial to obtain high recombinant protein expression levels (Bock and Warzecha 2010; Koop et al. 2007; Maliga and Bock 2011). Furthermore, the possibility of multi-gene engineering in a single transformation event ( $\mathrm{Lu}$ et al. 2013) and the ability of the plastid translation machinery to produce recombinant proteins with proper folding, disulfide bond formation and lipidation (New et al. 2012) makes chloroplasts an attractive expression platform for recombinant proteins (Clarke and Daniell 2011; Clarke and Zhang 2013; Bellucci et al. 2015).

However, high-level accumulation of recombinant proteins in chloroplasts can also have a negative impact on plant growth (Hennig et al. 2007; Petersen and Bock 2011; Scotti et al. 2015). Although, most foreign proteins are non-toxic to chloroplasts, in some cases, abnormal phenotypes like chlorosis of the leaves, male sterility and growth retardation have been reported (Lössl et al. 2003; Tregoning et al. 2003; Waheed et al. 2011). Inducible expression systems provide a tool to overcome these detrimental effects by controlling the transgene expression and production of foreign protein at any developmental stage or even post-harvest (Lössl and Waheed 2011). Several different induction systems for plastids have been reported (Buhot et al. 2006; Emadpour et al. 2015; Mühlbauer and Koop 2005; Tungsuchat et al. 2006; Verhounig et al. 2010). The transactivation system developed by Lössl et al. (2005) consists of a nuclear expression cassette for the RNA polymerase of bacteriophage T7 (McBride et al. 1994) under control of the ethanol-inducible alcA promoter and a plastid targeting signal (transit peptide), and a plastid expression cassette with the $\mathrm{T} 7$ promoter driving plastid transgene expression.

The Gateway ${ }^{\circledR}$ cloning system allows the rapid and efficient insertion of any transgene into expression vectors containing Gateway ${ }^{\circledR}$ recombination sites (Katzen 2007). Several vectors for transient or stable plant transformation (Buntru et al. 2013; Dubin et al. 2008, 2010; Earley et al. 2006; Karimi et al. 2007, 2013; Lyska et al. 2013) have been reported including a plastid transformation vector for constitutive transgene expression (Gottschamel et al. 2013).

The main objectives of our work were to contribute to the development of a plant-derived dengue vaccine 
candidate by demonstrating that (1) tobacco chloroplasts are a feasible production platform for EDIII based antigens and (2) that challenging proteins like the tetravalent EDIII1-4 fusion protein can be expressed via our ethanol inducible expression system.

\section{Materials and methods}

\section{Plant growth, biolistic transformation and regeneration}

Sterile Nicotiana tabacum cv. Petite Havana (Nt) and $\mathrm{Ni}$ cotiana tabacum-T7 recipient plants (Nt-T7; expressing an ethanol-inducible, plastid-targeted T7 RNA polymerase) were grown from surface sterilized seeds on solid MS medium (Murashige and Skoog 1962) containing $20 \mathrm{~g} / \mathrm{L}$ sucrose. The Nt-T7 plant line (Lössl et al. 2005) carries the RNA polymerase from bacteriophage T7 (McBride et al. 1994) and the nptII gene conferring kanamycin resistance in the nuclear genome. The T7 RNA polymerase is expressed from the ethanol inducible alcA promoter by the transcription factor AlcR derived from the alcohol dehydrogenase regulon of Aspergillus nidulans (Caddick et al. 1998; Roslan et al. 2001; Salter et al. 1998) and is targeted to chloroplasts via the N-terminally fused transit peptide of the small subunit of Rubisco from Pisum sativum (Dasgupta et al. 1998; Nawrath et al. 1994). Leaves from aseptically grown $N$. tabacum plants were bombarded with $0.6 \mu \mathrm{m}$ gold microcarriers coated with plasmid DNA using a Bio-Rad Biolistic PDS-1000/He gun (Daniell 1997; Svab and Maliga 1993). N. tabacum leaves were bombarded with the constructs pKP9-ediii-1, pKP9-ediii-3 and pEXP-T7ediii-1-4, and Nt-T7 leaves were bombarded with constructs pEXP-T7-ediii-4 and pEXP-T7-ediii-1-4. Biolistic transformation and selection of primary transplastomic lines was performed as described by Svab and Maliga (1993). Independently regenerated plant lines for each construct were subjected to three additional regeneration rounds on RMOP medium (Svab and Maliga 1993) containing spectinomycin (wild type-derived lines) or spectinomycin and kanamycin (Nt-T7-derived lines). Regenerated shoots were rooted on MS medium containing the respective antibiotics. Rooted homoplastomic plants confirmed by molecular analysis were transferred to soil and grown to maturity in the greenhouse under standard conditions. Inheritance assays on spectinomycin-containing MS medium were performed with the harvested seeds. Plant line Nt-T7-EDIII-1-4 was obtained by manually pollinating plant line Nt-EDIII-1-4 with pollen collected from plant line Nt-T7. Seeds obtained from this pollination were germinated on spectinomycin and kanamycin-containing MS medium and the presence of the T7 RNA polymerase in the nuclear genome of green seedlings was verified by PCR using primers (5'-TCTGTGAGCGTGAC GGTGGT- $3^{\prime}$ and $5^{\prime}$-TTACGCGAACGCGAAGTCCG- ${ }^{\prime}$ ) binding inside the coding sequence of the T7 RNA polymerase gene.

For the ethanol spray experiments, 5 week-old plants of plant lines Nt-T7-EDIII-4 and Nt-T7-EDIII-1-4 growing in Magenta boxes on MS medium containing spectinomycin were sprayed with $\sim 0.5 \mathrm{~mL} 5 \%$ ethanol on seven consecutive days, and a whole plant for every plant line was taken as a sample.

\section{Vector construction}

The tobacco-specific plastid transformation vector is based on plasmid pKP9 (Zhou et al. 2008). The sequences of the synthetic genes for ediii-1 and ediii-3 were codon optimized for expression in $N$. tabacum plastids followed by chemical DNA synthesis (Bio Basic, Canada). The constructs contain the restriction site $\mathrm{NdeI}$ at the $5^{\prime}$ end and a TEV protease cleavage site connected by a penta-glycine linker to the C-terminus of the recombinant protein followed by a 6xHis-tag and an XbaI site at the $3^{\prime}$ end. The synthesized sequences were first introduced into pHK20 (Kuroda and Maliga 2001) as NdeI/XbaI fragments, thus creating intermediary vectors. The complete expression cassettes were then transferred into pKP9 as HindIII/SacI fragments creating the plastid transformation vectors pKP9-ediii-1 and pKP9-ediii-3. In these vectors, the transgene is controlled by the strong tobacco plastid rRNA operon promoter (Prrn; Svab and Maliga 1993) fused with the $5^{\prime}$ UTR of gene 10 from bacteriophage T7 and the $3^{\prime}$ UTR of the plastid $r b c L$ gene. The Gateway ${ }^{\circledR}$-compatible plastid transformation vector pDEST-T7 was obtained by excision of the Prrn promoter sequence (Ye et al. 2001) from plasmid pDEST-PN-T (Gottschamel et al. 2013). The exclusive presence of the phage T7-derived promoter (Tabor and Richardson 1985) in the new vector was confirmed by sequencing. The sequence of the synthetic fusion gene (ediii-1-4) consists of all four DENV-EDIII sequences linked by penta-glycin linkers. The ediii-4 and ediii-1-4 sequences were codon optimized for $N$. tabacum chloroplasts and synthesized by GeneArt (Germany). Both synthesized sequences contain the $\mathrm{T} 7 \mathrm{~g} 10$ leader sequence and a 15 nucleotide downstream box (Herz et al. 2005) followed by the gene of interest and a C-terminal 6xHis-tag flanked with attB1/attB2 Gateway ${ }^{\circledR}$ recombination sites. The transgene sequences were first introduced into pDONR $^{\mathrm{TM}} 221$ by a BP reaction yielding the intermediary vectors pENTR-ediii-4 and pENTR-ediii-1-4, and then transferred by an LR reaction into pDEST-T7, resulting in the final plastid transformation vectors pEXP-T7-ediii-4 and pEXP-T7-ediii-1-4. The PCR Cloning Kit with 
Gateway ${ }^{\circledR}$ BP Clonase ${ }^{\circledR}$ Enzyme mix, pDONR ${ }^{\mathrm{TM}} 221$ and the Gateway ${ }^{\circledR}$ LR Clonase ${ }^{\circledR}$ Enzyme mix were purchased from Life Technologies (USA), and the Gateway ${ }^{\circledR}$ BP and LR reactions (Karimi et al. 2002) were carried out as described in the manufacturer's protocol.

Vectors for bacterial expression of recombinant EDIII-1 and EDIII-3 were constructed by using the pET28a plasmid (EMD Biosciences, USA) as backbone. The coding sequences of ediii-1 and ediii-3 were inserted into the pET28a vector backbone using the restriction sites Nde I and Hind III. The resulting vectors pET 28a-EDIII-1 and pET28a-EDIII-3 harbouring ediii-1 and ediii-3, respectively, were introduced into bacterial strain $\operatorname{Rosetta}^{\mathrm{TM}}$, a derivative of BL21, according to the manufacturer's instructions (Novagen, Germany).

\section{Southern blot analysis}

Plant DNA was isolated by a CTAB-based procedure (Murray and Thompson 1980) from wild-type plants and transplastomic tobacco lines after three rounds of regeneration on spectinomycin-containing medium. $10 \mu \mathrm{g}$ of plant DNA was digested with BglII (Nt-EDIII-1, Nt-EDIII3) or ApaI (Nt-T7-EDIII-4, Nt-T7-EDIII-1-4), separated by electrophoresis in a $1 \%$ agarose gel and transferred onto a positively charged nylon membrane (Carl Roth GmbH, Germany) by capillary action using the semi-dry transfer method. The probe binding inside the $p s a B$ region (primers: $5^{\prime}$-ACTACTCAAGCTGCATTATATACC- $3^{\prime}$ and $5^{\prime}$ GCACCTTTTACTAAGATCAATG- $3^{\prime}$ ) and the probe binding inside the $t r n N$ region (primers: $5^{\prime}$-TACCCGGG AATTGTGACCTC- $3^{\prime}$ and 5'-GAGTCCGACCACAA CGACC- $3^{\prime}$ ) were amplified by PCR from tobacco wildtype DNA. The probes were purified by agarose gel electrophoresis and extraction of the fragments of interest from excised gel slices was carried out using the NucleoSpin gel and PCR Clean-up Kit (Marchery-Nagel, Germany). Subsequently, they were DIG labelled following the manufacturer's instructions provided with the DIG-High Prime DNA Labeling and Detection Starter Kit II (Roche, USA). After immobilization of the DNA to the membrane, hybridization with the corresponding DIG-labeled probe and incubation of the membrane with the HRP conjugated anti-DIG antibody, the chemiluminescence signal was detected by exposure to X-ray film. One homoplastomic tobacco line for each construct (Nt-EDIII-1, Nt-EDIII-3, Nt-T7-EDIII-4, Nt-T7-EDIII-1-4) was chosen for further analysis.

\section{RNA analysis}

Total RNA was isolated from frozen and ground plant tissue with the Spectrum ${ }^{\mathrm{TM}}$ Plant Total RNA Kit (Sigma,
USA). RNA samples ( $5 \mu \mathrm{g}$ total RNA) were electrophoresed in $1.5 \%$ agarose gels containing $2 \%$ formaldehyde in $1 \times$ MOPS buffer $(20 \mathrm{mM}$ MOPS, $1 \mathrm{mM}$ EDTA, $5 \mathrm{mM} \mathrm{NaOAc}, \mathrm{pH} 7$ ) and blotted onto a positively charged nylon membrane (Carl Roth GmbH, Germany) by the capillary transfer method. Transcripts were detected with DNA probes binding inside the transgenes coding region. The den 1 probe was amplified by PCR from plasmid pKP9-ediii-1 with primers 5'-GCTGAAACTCAACATGGAACTG- $3^{\prime}$ and $5^{\prime}$-ATGCTTTTTCACCAGCAC CT- $3^{\prime}$, the den 3 probe from plasmid pKP9-ediii-3 with primers $5^{\prime}$-TGAAGATGGACAAGGAAAAGC- $3^{\prime}$ and $5^{\prime}$ CTCCACCACCTCCTTTACCA- $3^{\prime}$. The primers bind inside the coding sequences and result in a $223 \mathrm{bp}$ long den 1 probe and a $197 \mathrm{bp}$ long den 3 probe. Probes were labelled with DIG using the PCR DIG probe synthesis kit following the manufacturer's protocol (Roche, USA). Hybridizations were performed in DIG Easy Hyb Granules Buffer (Roche, USA) at $50{ }^{\circ} \mathrm{C}$, and signals were detected by exposure to X-ray film.

\section{Protein extraction, SDS-PAGE and western blot analysis}

Total protein (TP) was isolated from leaf samples by a phenolic extraction method (Cahoon et al. 1992). Frozen and ground leaf samples were homogenized in extraction buffer $(0.7 \mathrm{M}$ sucrose, $0.5 \mathrm{M}$ Tris- $\mathrm{HCl} \mathrm{pH} 9.4,50 \mathrm{mM}$ EDTA, $0.1 \mathrm{M} \mathrm{KCl}, 2 \% \beta$-mercaptoethanol, $1 \times$ Complete protease inhibitor (Roche, Switzerland)). After addition of 1 vol. phenol, short vortexing and centrifugation at $13,000 \mathrm{rpm}$ for $10 \mathrm{~min}$ at $4{ }^{\circ} \mathrm{C}$, the upper green phase was recovered and proteins were precipitated by addition of $0.1 \mathrm{M} \mathrm{NH}_{4} \mathrm{OAc}$ in methanol and overnight incubation at $-20{ }^{\circ} \mathrm{C}$. After centrifugation, the protein pellet was washed, air-dried and dissolved in $1 \%$ SDS. The total protein concentration was determined with the Pierce ${ }^{\mathrm{TM}}$ BCA Protein Assay Kit (Thermo Scientific, USA) and known concentrations of BSA as the standard. Protein samples were denatured in $6 \times$ SDS-sample buffer (375 mM Tris- $\mathrm{HCl} \mathrm{pH}$ 6.8, $60 \%$ glycerol, $12.6 \%$ SDS, $0.09 \%$ bromophenol blue, $10 \% \beta$-mercaptoethanol) separated by electrophoresis in $12 \%$ SDS-containing polyacrylamide gels and transferred to nitrocellulose membranes (Hybond-ECL, GE Healthcare, USA). The membranes were incubated with TBS-T $(20 \mathrm{mM}$ Tris-HCl $\mathrm{pH} 7.6,137 \mathrm{mM} \mathrm{NaCl}, 0.1 \%$ Tween-20,) containing $0.5 \%$ BSA as blocking buffer, and subsequently treated with the primary and the secondary antibody diluted in TBS-T. The recombinant proteins (Figure S1) were detected with the 1:1000 diluted polyclonal anti-dengue antibody produced in rabbits against the amino acid sequence KFKVVK EIAETQHGT by Davids Biotechnology (Germany), the 
1:10,000 diluted anti-rabbit-IgG-AP secondary antibody (Promega, USA) and colorimetric reaction using the AP color development Kit (Bio-Rad, USA). Alternatively, the 1:10,000 diluted anti-rabbit-IgG-HRP secondary antibody (Promega, USA) and the Amersham ${ }^{\mathrm{TM}} \mathrm{ECL}^{\mathrm{TM}}$ Prime Western Blotting Detection Reagent (GE Healthcare, USA) were used. Equal loading was monitored by Coomassie brilliant blue R250 (Bio-Rad, USA) staining and assessing the amount of the large subunit of Rubisco in the plant samples. Protein expression levels were estimated by comparison of the signal intensities in the samples to the signal of purified recombinant EDIII protein (expressed in E.coli) on the western blots.

\section{Mass spectrometric analysis of proteins}

Protein bands were cut out from SDS-PAGE gels stained with Coomassie brilliant blue R250 (Bio-Rad, USA) and in-gel digestion was carried out overnight with trypsin (Promega, Germany) in $25 \mathrm{mM}$ ammonium bicarbonate at $37{ }^{\circ} \mathrm{C}$ (Shevchenko et al. 2006). The peptides were desalted, purified and concentrated with modified STAGE microcolumns as described previously (Rappsilber et al. 2003) and then analysed by liquid chromatography combined with mass spectrometry (LC-MS/MS). The dried peptides were dissolved in $0.05 \%$ trifluoroacetic acid and $2 \%$ acetonitril in water and injected into an Ultimate 3000 nano ultra high performance liquid chromatography system (Dionex, USA) connected to a Q-Exactive quadrupole-orbitrap mass spectrometer (Thermo Scientific, Germany) equipped with a nano-electrospray ion source. For chromatographic separation, the peptides were loaded onto a trap column (Acclaim PepMap100 C18, $3 \mu \mathrm{m}, 100 \AA$, Dionex, USA) and then back-flushed onto an Acclaim PepMap RSLC C18 column $(2 \mu \mathrm{m}, 100 \AA$ A, $50 \mathrm{~cm}$ bed length, Dionex, USA). The gradient from 4 to $40 \%$ solvent B (80\% acetonitril, $0.1 \%$ formic acid) in 70 min was established at a flow rate of $300 \mathrm{~nL} / \mathrm{min}$. Solvent A was $0.1 \%$ formic acid in water. The mass spectrometer was set as follows: a full scan $(300-1600 \mathrm{~m} / \mathrm{z})$ at $\mathrm{R}=70,000$ was followed by (up to) $10 \mathrm{MS} 2$ scans at $\mathrm{R}=35,000$, using an NCE setting of 28. Singly charged precursors and precursors with $\mathrm{z}>5$ were excluded from MS/MS. Dynamic exclusion was set to $20 \mathrm{~s}$.

Raw files were converted to Mascot generic format (mgf) files using the msconvert module of ProteoWizard (http://proteowizard.sourceforge.net/) and submitted to database search (either dengue virus type 1 strain Nauru/ West Pac/1974 or dengue virus type 3 strain Philippines/ $\mathrm{h} 87 / 1956$ or NCBInr with a taxonomy restriction to green plants) on an in-house Mascot (v.2.4) server using $10 \mathrm{ppm} /$ 20mamu tolerance for MS and MS/MS, respectively.
Carbamidomethylated cysteine was selected as fixed modification and oxidation (M), deaminated (N, Q), $\mathrm{N}$-term acetyl (any N-terminus) as variable modifications and up to two miscleavages were allowed. Data was analyzed with the Scaffold 4.0 Proteomics Software.

\section{Results}

\section{Generation of transplastomic tobacco lines expressing EDIII antigens}

In order to constitutively express the dengue surface antigens from the chloroplast genome, the plastid transformation vectors pKP9-ediii-1 and pKP9-ediii-3 were constructed. The vectors mediate integration of the expression cassettes into the intergenic spacer region between the trnfM and $\operatorname{trn} G$ genes of the tobacco plastid genome (Fig. 1a). The vectors contain codon-optimized EDIII sequences under the control of the strong rRNA operon promoter (Prrn), and the aadA expression cassette conferring spectinomycin resistance. For inducible expression of EDIII-encoding genes, we first constructed a Gateway ${ }^{\circledR}$ destination vector that is compatible with plastid transformation and carries the $\mathrm{T} 7$ promoter for $\mathrm{T} 7$ polymerase-dependent transgene expression (Fig. 2a). The Gateway ${ }^{\circledR}$ cloning technology was thereafter used to create the final plastid transformation vectors. They contain the transgene coding sequence under the control of the T7 promoter and the aadA expression cassette flanked by homologous regions targeting the transgenes to the intergenic spacer region between the $\operatorname{trnN}$ and $\operatorname{trn} R$ genes of the tobacco plastid genome (Fig. 2b).

All constructs were introduced into tobacco plastids by particle bombardment and transgenic shoots were regenerated on RMOP medium containing antibiotics (Svab and Maliga 1993). A number of transformed plant lines were obtained for each construct and homoplasmy was verified after three regeneration rounds on antibiotic-containing medium by Southern blot analysis (Figs. 1b, 2c). No transformed plant lines regenerated directly for the T7ediii-1-4 construct bombarded into Nt-T7. The desired plant line Nt-T7-EDIII-1-4 was, therefore, obtained by first transforming Nt leaves with pEXP-T7-ediii-1-4, purifying a regenerated plant line to homoplasmy and then manually pollinating it with Nt-T7 pollen. Seeds from that cross were germinated on kanamycin and spectinomycin-containing medium and the presence of the T7 RNA polymerase was confirmed by PCR (data not shown). One plant line for each construct showing the expected hybridization pattern was chosen for further analyses: Nt-EDIII-1, Nt-EDIII-3, Nt-T7-EDIII-4 and Nt-T7-EDIII-1-4. Transplastomic tobacco lines growing in soil under greenhouse conditions 

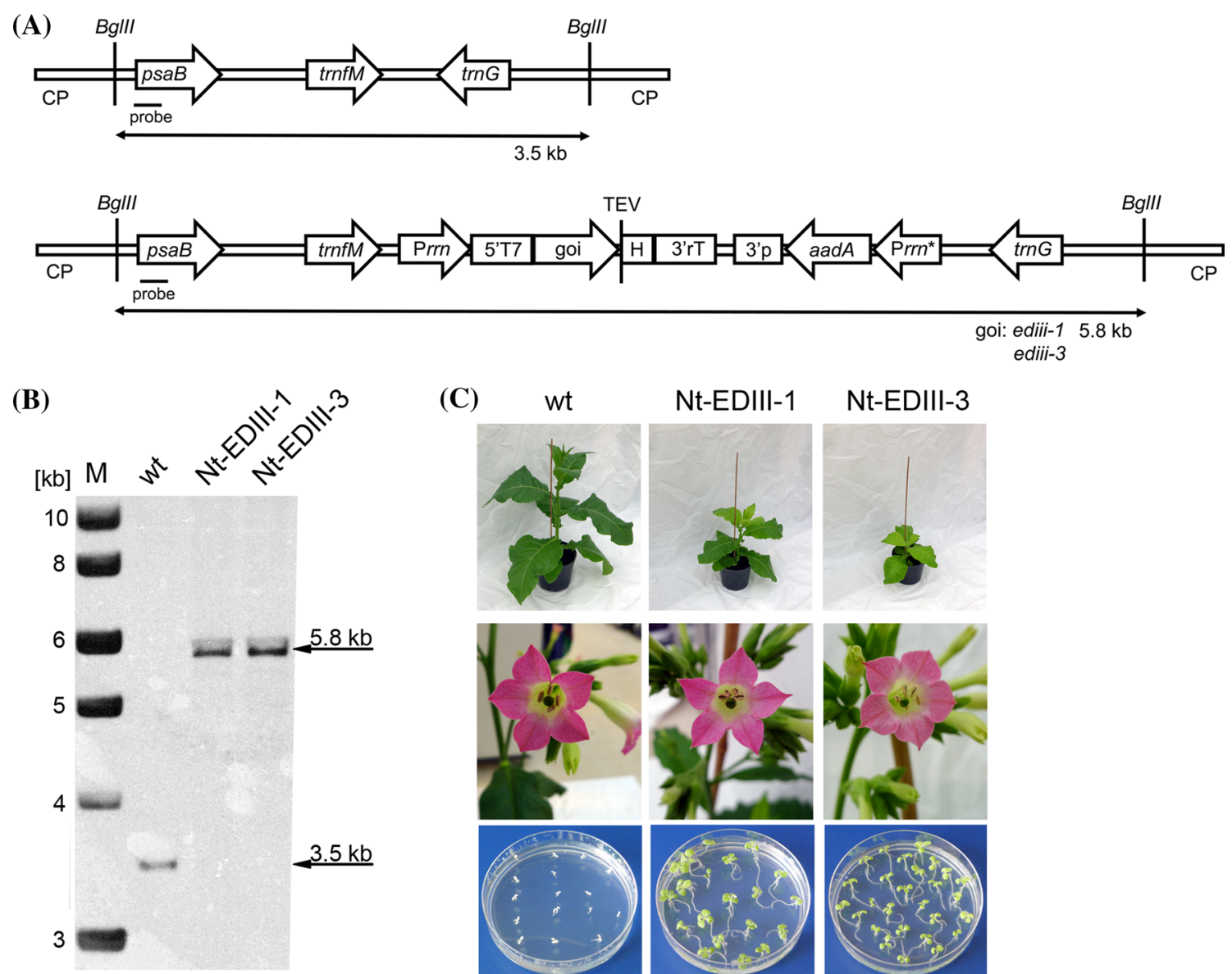

(C)

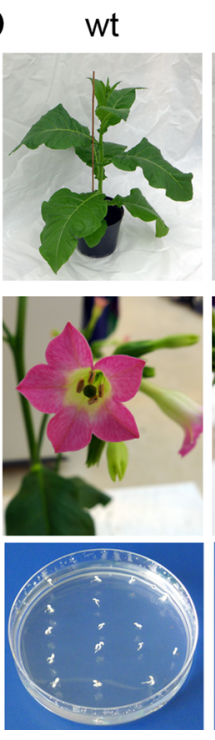

\section{Nt-EDIII-1 Nt-EDIII-3}

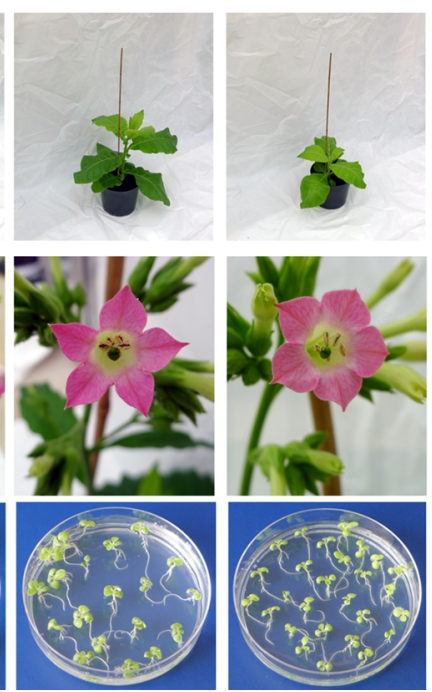

Fig. 1 Vector construction and regeneration of homoplastomic tobacco plants for the constitutive expression of the dengue antigens. a Schematic representation of the targeting region in the wild-type tobacco plastid genome and the transplastomic genome of the regenerated tobacco plant lines. The transgene expression cassette is integrated into the plastid genome (CP) in the intergenic spacer region between $\operatorname{trnfM}$ and $\operatorname{trn} G$. The transgene encodes a C-terminal TEV cleavage site (TEV) followed by the 6 xHis-tag $(\mathrm{H})$ and is under control of the tobacco plastid ribosomal RNA operon promoter (Prrn; (Ruf et al. 2001)) followed by the $5^{\prime} \mathrm{UTR}$ of the bacteriophage T7 gene 10 (5'T7; (Kuroda and Maliga 2001)) and the $3^{\prime}$ UTR of the tobacco $r b c L$ gene $\left(3^{\prime} \mathrm{rT}\right)$. The aadA marker gene is controlled by the chimeric rRNA operon promoter (Prrn*; (Svab and Maliga 1993)) and the $3^{\prime}$ UTR of the tobacco $p s b A$ gene ( $\left.3^{\prime} \mathrm{p}\right)$. The binding site of the Southern blot probe is shown as a black bar and the expected BglII fragments are indicated by arrows with their sizes given in $\mathrm{kb}$.

showed phenotypic alterations compared to wild-type plants regarding growth rate, leaf size and coloration of the leaves (Figs. 1c, 2d). However, no morphological differences were observable for flower development, and fertile seeds were obtained from all transplastomic plant lines. Inheritance analysis with F1 seeds germinating on spectinomycin-containing medium $(500 \mathrm{mg} / \mathrm{L})$ further confirmed homoplasmy and maternal transgene inheritance by lack of phenotypic segregation of the spectinomycin resistance (Fig. 1c, 2d). b Southern blot analysis of the regenerated tobacco plant lines NtEDIII-1 and Nt-EDIII-3. Total plant DNA was digested with BglII and hybridized to a DIG-labeled probe binding in the psaB region next to the transgene insertion site. Fragment sizes for the wild type (wt) and the transplastomic plant lines are indicated in kb. c Phenotypic comparison of transplastomic plant lines and wild-type tobacco and inheritance assay confirming maternal transgene transmission. Growth retardation and mild pigment deficiency were observable in the transplastomic tobacco plants, but flowers developed normally and fertile seeds were obtained. For inheritance assays, seeds from transplastomic plant lines and wild-type seeds were germinated on spectinomycin-containing medium. The uniform green phenotype of the transplastomic seedlings indicates the lack of transgene segregation and, thus, confirms absence of residual wild-type copies of the plastid genome

\section{Constitutive expression of recombinant EDIII proteins in tobacco chloroplasts}

Individual leaves of transplastomic plants were harvested and labeled L1 $=$ oldest leave to L6 = youngest leave (Fig. 3a). In order to examine the mRNA accumulation levels, northern blot analyses were performed with hybridization probes specific for ediii-1 or ediii-3 on total cellular RNA isolated from separately harvested leaves of Nt-EDIII- 1 and NtEDIII-3 plants, respectively. These experiments showed 


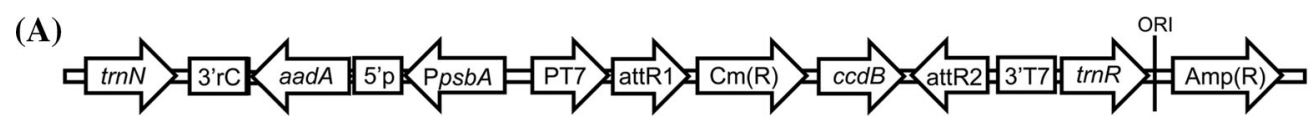

(B)
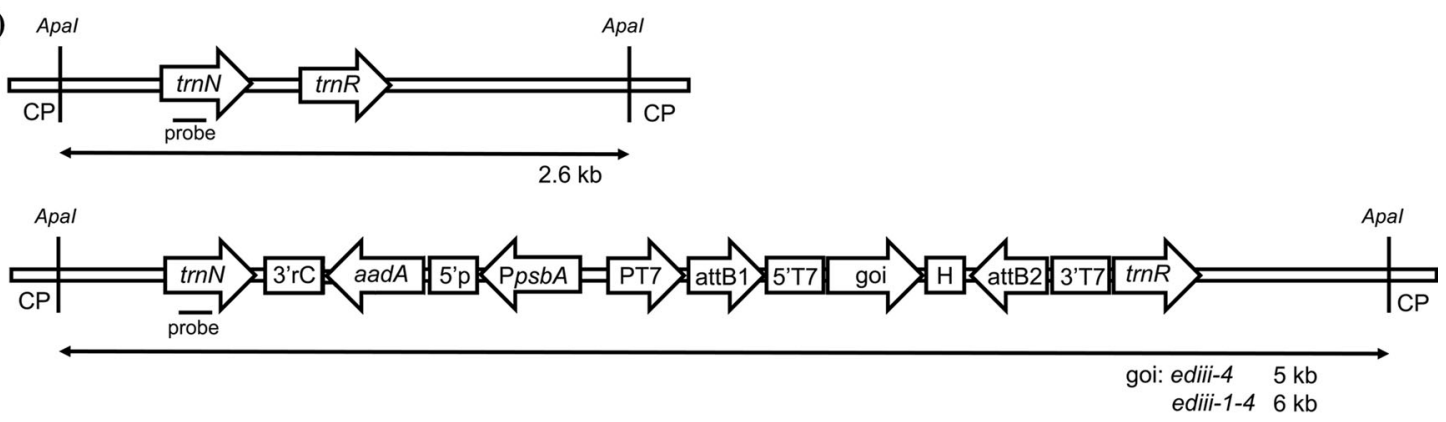

(C)

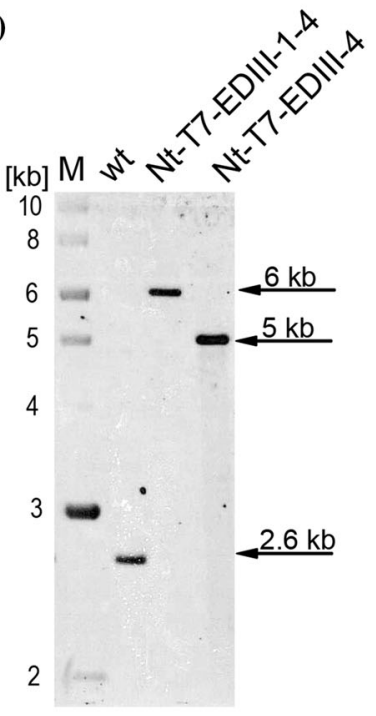

(D)

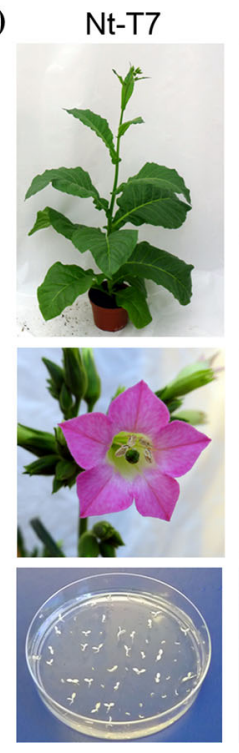

Nt-T7-EDIII-4 Nt-T7-EDIII-1-4

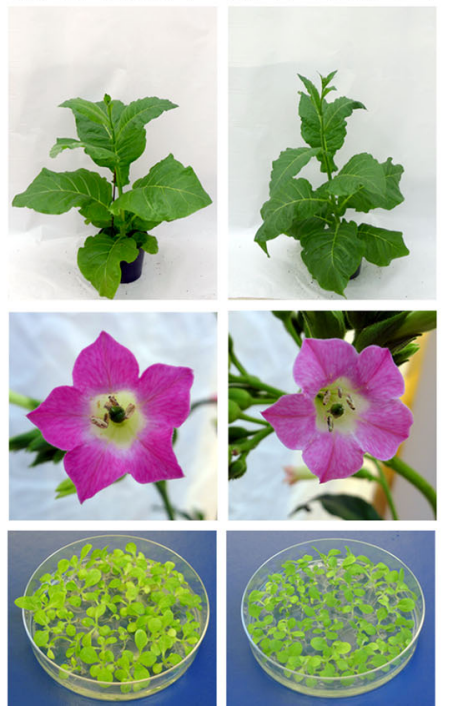

Fig. 2 Vector construction and regeneration of homoplastomic tobacco plants for the inducible expression of the dengue antigens. a Schematic representation of pDEST-T7. The Gateway ${ }^{\circledR}$ cassette in the destination vector consists of the control of cell death gene $(c c d B)$ and the chloramphenicol resistance gene $(\mathrm{Cm}(\mathrm{R}))$ flanked by the Gateway ${ }^{\circledR}$ recombination sites attR1 and attR2. Amp(R): ampicillin resistance gene; ORI: bacterial origin of replication. b Schematic representation of the targeting region in the wild-type tobacco plastid genome and the transplastomic genome of the regenerated plant lines. The transgene expression cassette is integrated into the plastid genome (CP) in the intergenic spacer region between $t r n N$ and $t r n R$. The ediii- 4 and the ediii-1-4 sequences have a C-terminal 6xHis-tag (H) and are under the control of a phage T7-derived promoter (Tabor and Richardson 1985), the $5^{\prime}$ UTR of bacteriophage T7 gene $10\left(5^{\prime} \mathrm{T} 7\right)$ and the $\mathrm{T} 7$ terminator sequence $\left(3^{\prime} \mathrm{T} 7\right)$. The transgene expression cassette further contains the Gateway ${ }^{\circledR}$ recombination sites (attB1/ attB2). The aadA marker gene is controlled by the tobacco $p s b A$

detectable levels of ediii-1 and ediii-3 transcripts in both transplastomic plant lines, but with observable differences between the individual leaves. The mRNA accumulation levels increased from old to young leaves in Nt-EDIII-1, while they decreased in Nt-EDIII-3 (Fig. 3b).

Western blot analyses performed with total protein extracts of plant lines Nt-EDIII-1 and Nt-EDIII-3 also promoter (PpsbA, (Staub and Maliga 1993), the $5^{\prime}$ UTR of tobacco psbA gene $\left(5^{\prime} \mathrm{p}\right)$ and the $3^{\prime} \mathrm{UTR}$ of the Chlamydomonas reinhardtii $r b c L$ gene $\left(3^{\prime} \mathrm{rC}\right)$. The binding site of the Southern blot probe is shown as a black bar and the expected ApaI fragments are denoted by arrows with their sizes indicated in kb. c Southern blot analysis of regenerated plant lines. Total plant DNA was digested with ApaI and hybridized to a DIG-labeled probe binding to the $t r n N$ region of the plastid genome. Fragment sizes for the wild-type (wt) and the transplastomic plant lines are indicated in kb. d Phenotypic comparison of transplastomic tobacco lines Nt-T7-EDIII-4 and Nt-T7-EDIII1-4 with the nuclear transgenic (T7 RNA polymerase-expressing) recipient line Nt-T7. Only a very subtle growth retardation in the transplastomic plant lines was observable. For inheritance assays, seeds from the transplastomic plant lines and $\mathrm{Nt}$-T7 seeds were germinated on spectinomycin-containing medium. The uniform green phenotype of the transplastomic seedlings proves the absence of wildtype plastid genomes

revealed different protein accumulation levels depending on the leave age (Fig. 3c, d). We exemplarily determined the expression level of the monomeric forms of the recombinant proteins in the leaves with the highest expression level. The EDIII-1 protein expression reached a maximum of approximately $1.6 \%$ of total protein in the fully expanded leaf L4, while EDIII-3 accumulated to 
(A)

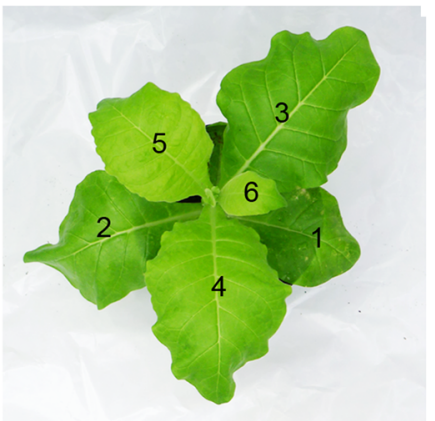

(B)

Nt-EDIII-3

rRNA

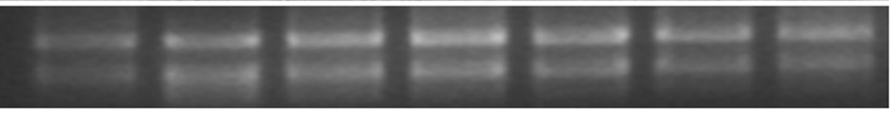

(C) EDIII-1

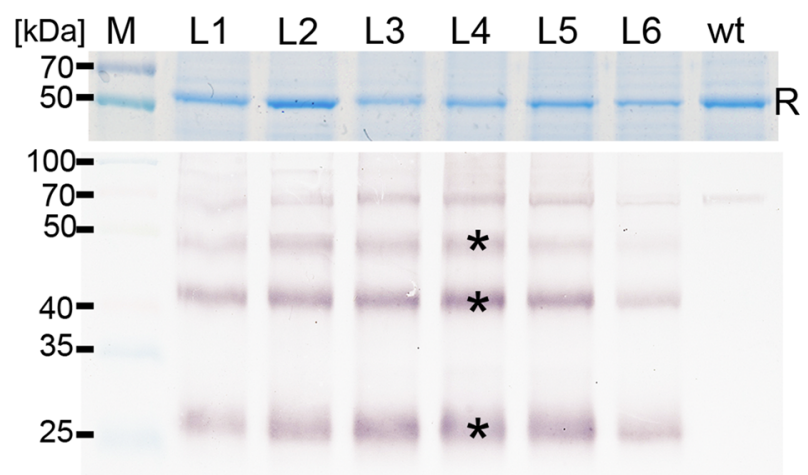

$15-$

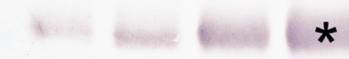

(D)

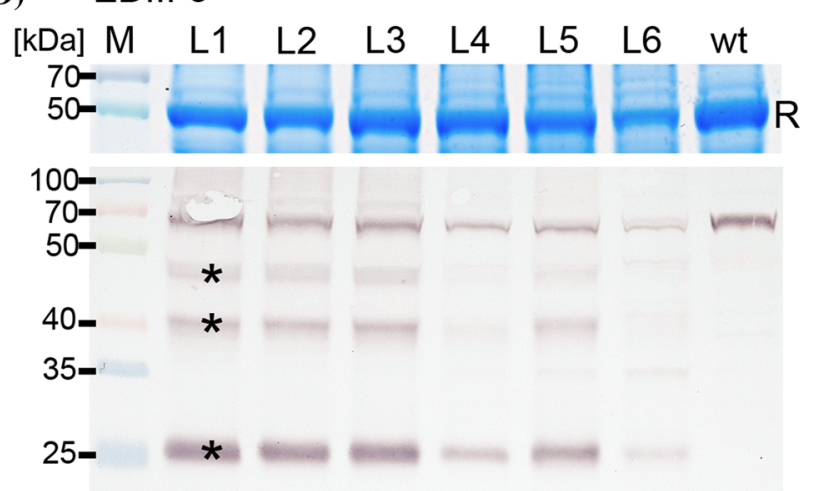

(E)

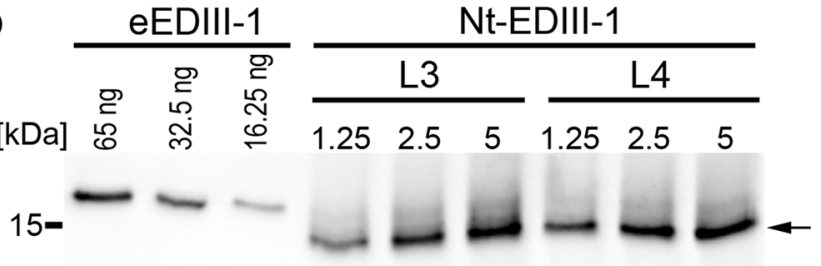

Fig. 3 Constitutive expression of EDIII recombinant proteins. a Individual leaves from a 7-week old plant were sampled from the bottom to the top (L1: oldest leaf; L6: youngest leaf) and total cellular RNA and total protein were extracted from each leaf. b Northern blot analyses of ediii- 1 and ediii-3 transcription levels. The ediii-specific hybridization probes detect a transcript of $650 \mathrm{bp}$ which corresponds to the expected mRNA size ( $370 \mathrm{bp}$ coding region and approximately $280 \mathrm{bp} 5^{\prime}$ and $3^{\prime}$ UTRs). The mRNA detected with the den 1 probe in Nt-EDIII-1 accumulates to higher levels in young leaves (L6) than in older ones (L1). By contrast, accumulation of mRNA detected with the den 3 probe in Nt-EDIII-3 decreases from old to young leaves. The ethidium bromid-stained rRNA is depicted as a control for equal loading. c Western blot analysis of EDIII-1 protein accumulation in $5 \mu \mathrm{g}$ total protein extracted from leaves 1 to 6 of Nt-EDIII-1. d Western blot analysis of EDIII-3 protein accumulation in $50 \mu \mathrm{g}$ total protein extracted from leaves 1 to 6 of Nt-EDIII-3. e Western

approximately $0.8 \%$ of total protein in the oldest leaf L1 (Fig. 3e).

Furthermore, in addition to the expected $13 \mathrm{kDa}$ band corresponding to the monovalent EDIII proteins, also specific blot analyses assessing foreign protein accumulation levels in total protein extract of leaves L3 and L4 of Nt-EDIII-1 and leaves L1 and L2 of Nt-EDIII-3 by comparison to a dilution series of recombinant E.coli-derived protein (eEDIII-1, eEDIII-3). The amount of total protein extract loaded is indicated above each lane in $\mu \mathrm{g}$. Both eEDIII-1 and eEDIII-3 have an approximate molecular mass of $15 \mathrm{kDa}$ due to additional C-terminal amino acids resulting from the bacterial expression vector. EDIII-1 and EDIII-3 have a theoretical molecular weight of $13 \mathrm{kDa}$ and are marked with arrows. Equal loading is monitored by the uniform Coomassie blue staining of the $\sim 50 \mathrm{kDa}$ large subunit of ribulose-1,5-bisphosphate carboxylase (R). The bands marked with an asterisk were subjected to mass spectrometric analysis. The band migrating at $70 \mathrm{kDa}$ results from non-specific binding of the antibody to a plant protein of unknown identity. RNA or total protein extracted from a wild-type plant (wt) were used as negative controls

bands at higher molecular masses were detected in total protein extracts with the anti-dengue antibodies. Mass spectrometric analysis of the observed protein bands at approximately $15,26,40$ and $50 \mathrm{kDa}$ were carried out in order to 
investigate the identity of the protein bands and the possibility of multimerization of the recombinant proteins. A total number of 18 different EDIII-1 derived tryptic peptides and 15 different EDIII-3 derived tryptic peptides were detected by the MS/MS analysis. As expected, not every theoretically arising peptide was detected and some of the detected peptides resulted from only partial trypsin digestion, but at least two protein-specific peptides were detected in every sample (Fig. 4a, b). The overall percentage of amino acid sequence coverage by all detected peptides was satisfactory $(>50 \%)$ with the only exception of the $26 \mathrm{kDa}$ sample of EDIII-3.

\section{Inducible expression of EDIII recombinant proteins in tobacco chloroplasts}

Our trans-activation system for chloroplast expression is based on ethanol induction of the expression of the nuclear encoded T7 RNA polymerase. The polymerase is targeted to the chloroplast where it recognizes the T7 promoter controlling the expression of the ediii-4 and ediii-1-4 transgenes. To test for inducibility, in vitro grown plants were sprayed with $5 \%$ ethanol on several consecutive days to induce recombinant protein expression. No negative effect of the ethanol treatment on the plants was observable (Fig. 5a). Western blot analysis of total protein extracted from plant lines Nt-T7-EDIII-4 and Nt-T7-EDIII-1-4 detected the recombinant EDIII proteins with increasing expression levels after repeated ethanol exposure. Expression of the $13 \mathrm{kDa}$ EDIII-4 appears to be somewhat leaky, since protein accumulation is already detectable in the untreated plants. Bands corresponding to the sizes of EDIII4 multimers at 23, 34, 40 and $\sim 47 \mathrm{kDa}$ are also detected by the antibody (Fig. 5b). In contrast to EDIII-4 expression, no EDIII-1-4 (48 kDa) expression is detectable before ethanol

(A) EDIII-1:

MSYVMCTGSFK:LEK:EVAETQHGTVLVQVK:YEGTDAPCK:IPFSSQDEK!GVTQNGR: LITANPIVTDK:EKPVNIEAEPPFGESYIVVGAGEK:ALK:LSWFK!K!GSSIGK!GGGGGENLYFQGHHHHHH
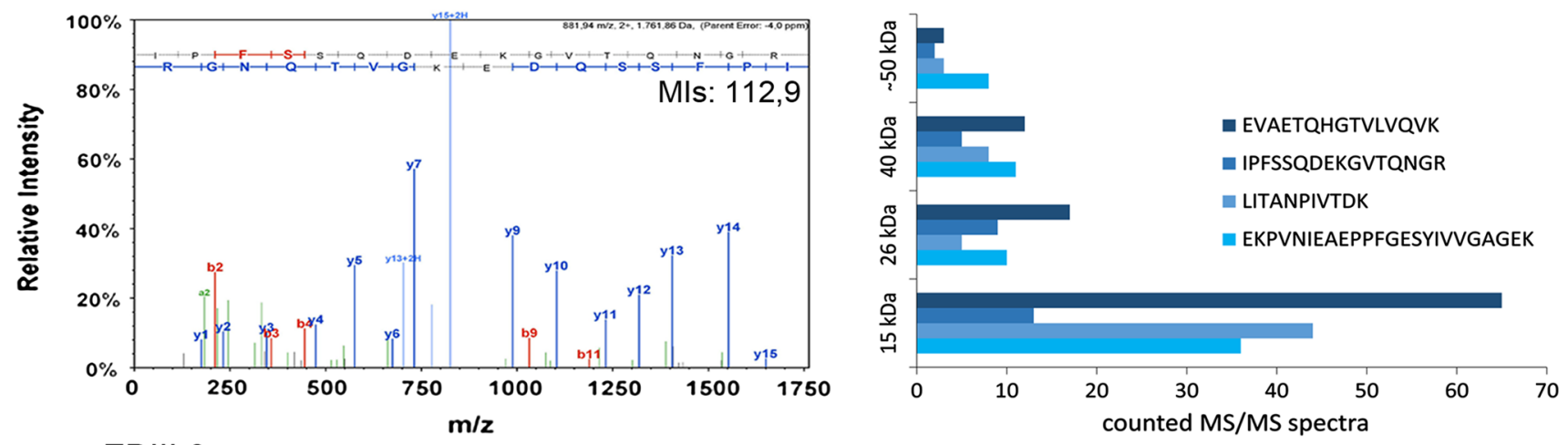

(B) EDIII-3:

MSYAMCLNTFVLK:K:EVSETQHGTILIK:VEYK:GEDAPCK:IPFSTEDGQGK:AHNGR:LITANPVVTK:

K:EEPVNIEAEPPFGESNIVIGIGDK:ALK!INWYR:K!GSSIGK!GGGGGENLYFQGHHHHHH
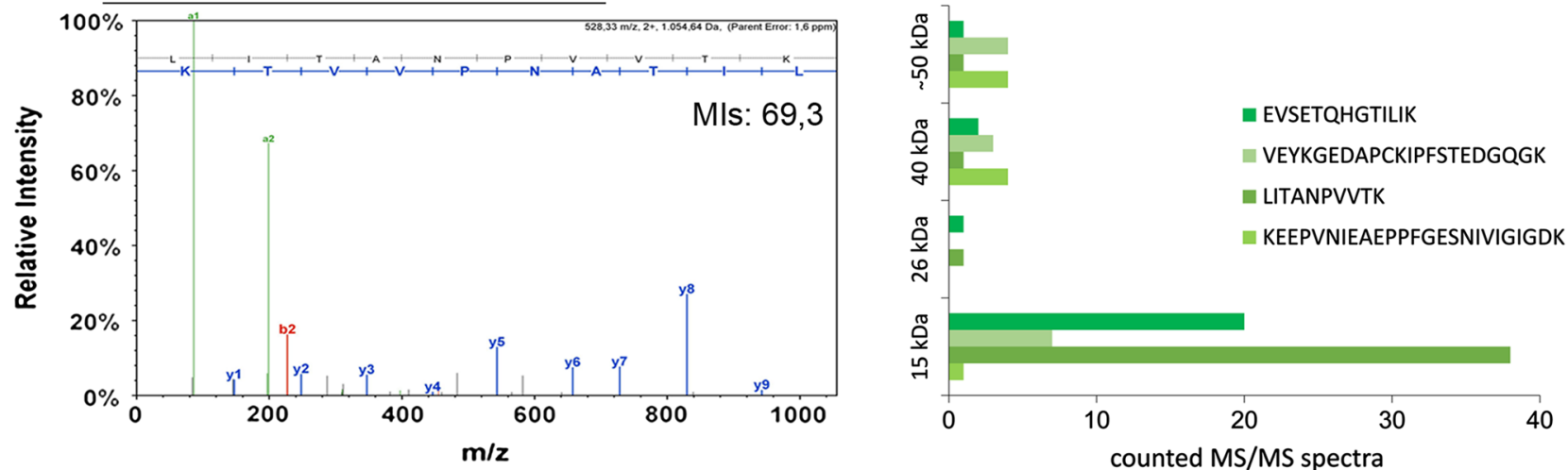

Fig. 4 Mass spectrometric analysis of EDIII proteins. a EDIII-1. b EDIII-3. The bands marked with an asterisk (at approximately 15 , 26, 40 and $50 \mathrm{kDa}$ ) in the western blots in Fig. 3 were cut out from identical Coomassie brilliant blue 250 stained gels and subjected to mass spectrometric analysis. The amino acid sequences of the recombinant proteins are shown with the theoretical trypsin cleavage sites marked by Vertical dots and the four most abundant detected peptides underlined. The MS/MS spectra are shown for one proteinspecific tryptic peptide (bold and underlined) for each recombinant protein and the Mascot Ion score (MIs) is indicated for that peptide. The occurrence of the four most abundant peptides in the sampled bands is depicted in the graph at the right. The percentage of amino acid sequence coverage by the four peptides is $54 \%$ for EDIII- 1 and $57 \%$ for EDIII-3, respectively 

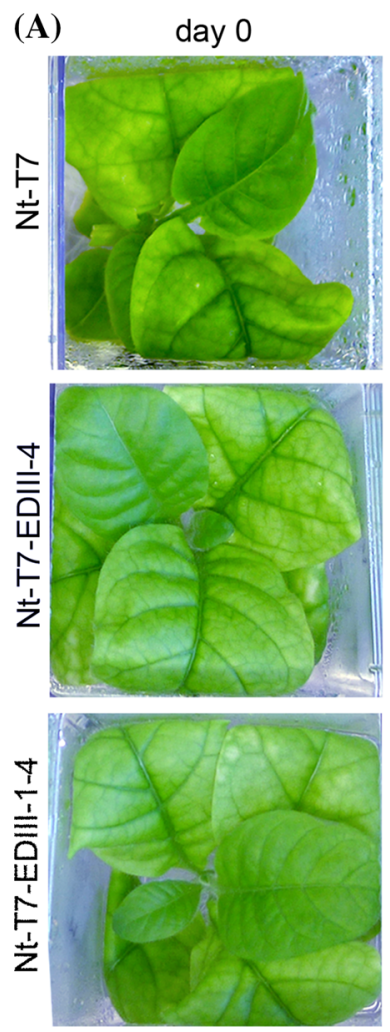

Fig. 5 Ethanol-induced recombinant protein expression in transgenic chloroplasts. Transplastomic plants were sprayed with ethanol on seven consecutive days. Whole plants were taken as samples and $50 \mu \mathrm{g}$ total protein extract per sample were analyzed by western blotting. a The plants sprayed with $5 \%$ ethanol do not show deleterious phenotypic changes in in vitro culture. b Western blot with total protein extracts of Nt-T7-EDIII-4. c Western blot with total protein extracts of Nt-T7-EDIII-1-4. Western blot analyses were performed with samples taken before the first ethanol treatment (d0),
(B) EDIII-4

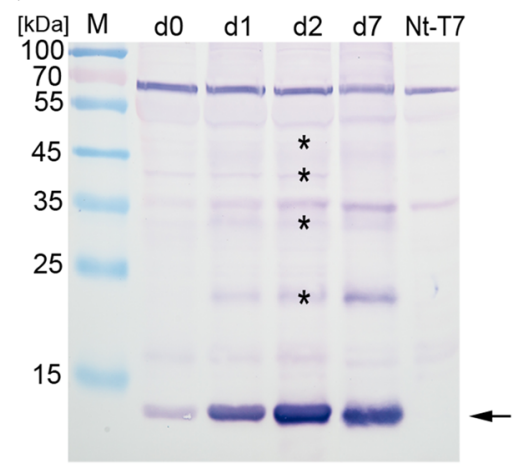

(C) EDIII-1-4

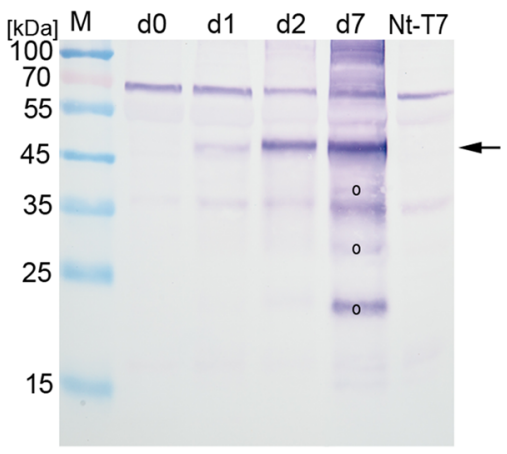

induction. Instead, recombinant protein accumulates after ethanol treatment of Nt-T7-EDIII-1-4 plants in a time-dependent manner (i.e., with the number of ethanol sprays; Fig. 5c). The bands at lower molecular weights appearing at day 7 indicate that EDIII-1-4 is, to some extent, susceptible to proteolytic degradation.

\section{Discussion}

Dengue fever virus infections are a significant cause of morbidity and mortality in developing countries of the tropics and subtropics (Gubler 2012; WHO 2015). Since the main target group for a dengue vaccine are the relatively poor people in developing countries, the ideal dengue vaccine should be affordable, heat-stable (i.e., independent of an uninterrupted cooling chain) and easy to administer. Recombinant dengue virus EDIII protein-based antigens have been previously expressed in E.coli (Khanam
1 day after the first treatment (d1), after 2 days (d2) and after 7 days (d7) of ethanol treatment. Nt-T7 sprayed with ethanol for 7 days was used as a negative control. The bands representing the recombinant proteins with the expected molecular weight of $13 \mathrm{kDa}$ for EDIII-4 and $48 \mathrm{kDa}$ for EDIII-1-4 are marked with arrows, the multimers of EDIII-4 with asterisks and the EDIII-1-4-derived fragments with circles. The other bands, migrating at several different molecular weights and also visible in the wt sample, are the result of nonspecific binding of the antibody to plant proteins

et al. 2006; McDonald et al. 2009; Simmons et al. 1999; Srivastava et al. 2000; Tripathi et al. 2008, 2011; Zhao et al. 2014), in yeast (Arora et al. 2013; Batra et al. 2010a; Cardoso et al. 2013; Etemad et al. 2008; Nguyen et al. 2015), in insect cells (Ivy et al. 2000) and also via nuclear transformation in plants (Kim et al. 2013; Martinez et al. 2010; Saejung et al. 2007). In the present study, the dengue virus envelop protein domain III-based tetravalent fusion protein (EDIII-1-4) and the monovalent forms (EDIII-1, EDIII-3 and EDIII-4) have been expressed in tobacco chloroplasts. The chloroplast expression system offers transgene confinement, high levels of foreign protein expression and highly precise, site-specific transgene integration by homologous recombination (Bock 2014). Tobacco is a non-food/non-feed crop, readily amenable to genetic manipulation, and is an excellent biomass and seed producer (Tuse et al. 2014). Taken together, these characteristics make tobacco plastids a promising production platform for the large-scale synthesis of recombinant 
subunit vaccines, including dengue fever vaccines. So far, only the expression of a dengue virus serotype 3 premembrane and envelope polyprotein has been reported in plastids (Kanagaraj et al. 2011). We demonstrate that dengue virus envelop protein domain III-based antigens can be expressed in tobacco chloroplasts and that the expression of challenging proteins via the ethanol-inducible expression system offers a possibility to avoid deleterious phenotypes associated with overexpression (Hennig et al. 2007; Petersen and Bock 2011; Scotti et al. 2015). The transplastomic plant lines with the transgene expression cassette controlled by the strong constitutive ribosomal RNA operon promoter showed distinct growth retardations and mild pigment deficiency. In many cases, plastid expression of recombinant proteins does not result in abnormal phenotypes, but an increasing number of studies has reported phenotypic alterations in transplastomic plants (Lössl et al. 2003; Magee et al. 2004; Scotti et al. 2015; Tissot et al. 2008; Tregoning et al. 2003; Waheed et al. 2011). The two main reasons underlying pigment deficiency or a delay in plant development are toxicity of the transgene product due to interference of the recombinant protein with essential processes in the chloroplast (e.g. biogenesis of the thylakoid membrane; (Hennig et al. 2007)) or the severe metabolic burden imposed on the chloroplast due to extreme recombinant protein expression levels (Oey et al. 2009a; Scotti and Cardi 2014). Expression levels above $40 \%$ of the total soluble protein can exhaust the gene expression capacity of the chloroplast resulting in Rubisco depletion and a general decrease in plastid-encoded proteins (Bally et al. 2009; Zhou et al. 2008). The rather low expression levels of our recombinant proteins and the fact that no Rubisco depletion was visible on the Coomassie brilliant blue-stained gels suggests that in our case, the observed phenotypic alterations are more likely due to the recombinant protein interfering with chloroplast biogenesis, metabolism or gene expression.

The activation of transgene expression after leaf development and chloroplast biogenesis is completed could be a way to avoid detrimental effects caused by the recombinant protein (Emadpour et al. 2015). Inducible expression systems allow the plants to grow to maturity without the burden of recombinant protein production. After induction of transgene expression, the full biomass capacity can be exploited for production of the recombinant protein. In this work, we have employed an ethanol-inducible expression system that is based on a nuclear-encoded and plastid-targeted T7 RNA polymerase for the expression of EDIII-4 and EDIII-1-4. The functionality of this system to overcome growth reduction and male sterility caused by expression of the phb operon (for polyhydroxybutyrate synthesis) has been previously demonstrated (Lössl et al.
2005). In this study, induction of EDIII-4 and EDIII-1-4 expression was achieved after repeated ethanol exposure. The low level of recombinant protein detectable in uninduced Nt-T7-EDIII-4 plants is in accordance with the previously reported leakiness of the system (Lössl et al. 2005). Most likely, it is also responsible for the slightly slower growth of the transplastomic plants (Note that background antigen accumulation in the Nt-T7-EDIII-1-4 plants was below the detection limit, presumably due to lower expression and/or protein stability). The fact that our attempts to regenerate homoplasmic plants expressing the EDIII-1-4 fusion from the strong constitutive rRNA operon promoter failed (data not shown), further emphasizes the usefulness of this trans-activation system to overcome hurdles in transgene expression and avoid phenotypic alterations related to recombinant protein accumulation.

The accumulation levels of the constitutively expressed recombinant proteins varied depending on the age of the leave. The highest level of EDIII-1 accumulated in young and fully expanded leaves (leaves 3-5; Fig. 3). Previous reports, where accumulation of the p24 protein (Zhou et al. 2008) and the VP6 protein (Birch-Machin et al. 2004) was only detectable in young leaves, suggested that these proteins accumulate when chloroplast protein synthesis rates are high (i.e., during early leaf development), but protein levels fall when the activity of plastid gene expression declines during and after leaf maturation. Conversely, highly stable proteins can keep accumulating and even increase over leaf development and senescence (Oey et al. 2009a, b). The detected accumulation levels of EDIII-3 were lower than for EDIII-1, but higher in older than in young leaves (Fig. 3c, d). This suggests that this protein, although overall expressed at a lower level, might be more stable during leaf development than EDIII-1. Although the detected mRNA levels also vary with leaf age (Fig. 3b), the transcript levels do not really correlate with protein accumulation levels. Furthermore, ediii-1 and ediii-3 are controlled by the same regulatory elements, suggesting that transcript abundance is determined by factors within the coding sequence and/or by intrinsic factors depending on the leaf's developmental stage. It is well established that, in plastids, high mRNA accumulation does not necessarily result in high protein levels (Eberhard et al. 2002; Kahlau and Bock 2008), because translation control is more dominant than transcriptional regulation (De Marchis et al. 2012). Also, high turnover can lead to rapid degradation of proteins (Kim et al. 1994). An N-end rule for plastid proteins has been proposed where the protein stability is influenced by the penultimate $\mathrm{N}$-terminal amino acid residue (Apel et al. 2010). Since the N-terminal amino acid is serine for both EDIII-1 and EDIII-3, an amino acid that conferred intermediate levels of protein stability, the $\mathrm{N}$-end rule alone does not explain the variation in EDIII 
accumulation. However, it was also demonstrated that the extended $\mathrm{N}$-terminus of plastid proteins can have an even greater impact on protein stability than the penultimate residue (Apel et al. 2010). Whether or not N-terminal sequence differences between EDIII variants account for the observed differences in protein accumulation, remains to be investigated. In general, accumulation of foreign proteins in plastids depends on the rates of transcription, translation and protein stability (Scotti et al. 2013; Nakakura et al. 2016), and the recombinant protein accumulation level is nearly impossible to predict (Bock 2014).

Unexpectedly, the immunoblot analyses revealed the presence of additional protein bands with higher molecular masses than the predicted $13 \mathrm{kDa}$ for EDIII-1 and EDIII-3, respectively. Mass spectrometric analyses confirmed that all analyzed bands contain the specific EDIII-derived tryptic peptides. Mature dengue virus particles are formed by $\mathrm{E}$ protein dimers organized in a herringbone configuration on the viral surface (Kuhn et al. 2002), and the main dimerization properties are associated with domain II (Modis et al. 2003). Our recombinant protein consists only of the domain III of the envelope protein. However, the homodimers of the $\mathrm{E}$ protein interact closely with each other during the viral life cycle (Mukhopadhyay et al. 2005) and the post-fusion structure at low $\mathrm{pH}$ is characterized by a trimeric arrangement of $\mathrm{E}$ protein monomers (Modis et al. 2004). Therefore, it cannot be excluded, that domain III retains some characteristics that favor protein aggregation even when expressed in isolation. Although this phenomenon has not been reported for similar proteins expressed in E.coli (Khanam et al. 2006) or yeast cells (Batra et al. 2010a; Cardoso et al. 2013), a putative dimeric species has been detected in solubilized inclusion bodies of EDIII-2 (Jaiswal et al. 2004). The ability of the chloroplastproduced EDIII proteins to form strong aggregates may be an advantage for the stimulation of the immune system and induction of intestinal secretory $\operatorname{IgA}$ following oral immunization.

When expressed in Pichia pastoris, the tetravalent fusion protein linking the EDIII domains of the four dengue virus serotypes has already been reported to elicit neutralizing antibodies against all four serotypes (Batra et al. 2007; Etemad et al. 2008). Although, the plantderived recombinant proteins are required to undergo separate and independent evaluations regarding immunogenicity, the outcome of such studies is expected to be very similar. The fusion protein approach indicates a way to avoid unbalanced immune responses continuously reported for tetravalent formulations consisting of stoichiometrically mixed monovalent vaccines (Capeding et al. 2014; Hadinegoro et al. 2015; Villar et al. 2015). Furthermore, the transformation of the plastid genome represents a promising possibility for the high-level, cost-effective, clean and safe expression of therapeutically relevant proteins in commercial applications (Wani et al. 2015). A theoretical technoeconomic case study showed that plants can be highly competitive production platforms for biopharmaceuticals (Tuse et al. 2014). Compliance with good manufacturing practices required for all products entering clinical development (Fischer et al. 2012; Yusibov et al. 2011) and optimization of production processes leading to a reduction of downstream processing-related costs will help to commercialize more plant-derived pharmaceuticals in the future (Fischer et al. 2013, 2015).

\section{Conclusion}

In the present study, we constitutively expressed the monovalent EDIII domains of the dengue virus serotypes 1 and 3 (EDIII-1, EDIII-3) in tobacco chloroplasts. Furthermore, the ethanol-inducible expression of EDIII-4 and the tetravalent construct EDIII-1-4 in tobacco chloroplasts shows the potential benefits of an inducible antigen production system that may help to overcome detrimental effects of recombinant proteins on physiology or development of the plant. Since the plastid transformation vector for the inducible expression system includes Gateway ${ }^{\circledR}$ recombination sites, this study adds a new Gateway ${ }^{\circledR}$ compatible destination vector to the chloroplast transformation toolbox. The successful synthesis of recombinant EDIII proteins by both constitutive and inducible transplastomic expression systems reported here provide a promising entry point into the future production of EDIIIbased dengue vaccine candidates in tobacco chloroplasts.

Acknowledgments This work was supported by the GLOBVAC program (Project 192510), the Research Council of Norway (RCN), Bioforsk/NIBIO core funding and the Max Planck Society. The authors thank Pierre Endries (MPI-MP), Hege Særvold Steen, Ingrid Holtsmark, Sissel Haugslien and Inger Martinussen (NIBIO) for technical support and fruitful discussions.

Author contribution Jihong Liu Clarke is the project leader and corresponding author who has involved in all the steps including project design, execution (constitutive expression of EDIII dengue antigens) and manuscript preparation, revision and submission; Johanna Gottschamel has contributed to project design, execution and manuscript preparation (who wrote the first draft and did the revisions); Andreas Lössl has contributed to project design, supervision of inducible expression of EDIII antigens and manuscript revision; Ralph Bock has contributed to project design, constitutive expression of EDIII-antigens using their vectors and manuscript preparation and revision; Stephanie Ruf has contributed to project design, vector construction and constitutive expression of ED-III dengue antigens; Yanliang Wang has contributed to project design, RNA isolation, Northern blot analysis and partially to the manuscript writing; Morten Skaugen did all the Mass spectrometric analysis of proteins and contributed to the manuscript writing related to Mass spectrometric analysis and discussion. 


\section{References}

Apel W, Schulze WX, Bock R (2010) Identification of protein stability determinants in chloroplasts. Plant $\mathrm{J}$ 63:636-650. doi:10.1111/j.1365-313X.2010.04268.x

Arora U, Tyagi P, Swaminathan S, Khanna N (2013) Virus-like particles displaying envelope domain III of dengue virus type 2 induce virus-specific antibody response in mice. Vaccine 31:873-878. doi:10.1016/j.vaccine.2012.12.016

Bally J, Nadai M, Vitel M, Rolland A, Dumain R, Dubald M (2009) Plant physiological adaptations to the massive foreign protein synthesis occurring in recombinant chloroplasts. Plant Physiol 150:1474-1481. doi:10.1104/pp.109.139816

Batra G, Chaudhry S, Hapugoda M, Khanna N, Swaminathan S (2007) Tetravalent dengue specific domain III based chimeric recombinant protein. WO 2007034507

Batra G, Raut R, Dahiya S, Kamran N, Swaminathan S, Khanna N (2010a) Pichia pastoris-expressed dengue virus type 2 envelope domain III elicits virus-neutralizing antibodies. J Virol Methods 167:10-16. doi:10.1016/j.jviromet.2010.03.002

Batra G, Talha SM, Nemani SK, Dhar N, Swaminathan S, Khanna N (2010b) Expression, purification and characterization of in vivo biotinylated dengue virus envelope domain III based tetravalent antigen. Protein Expr Purif 74:99-105. doi:10.1016/j.pep.2010. 04.017

Bellucci M, De Marchis F, Ferradini N, Pompa A, Veronesi F, Rosellini D (2015) A mutant Synechococcus gene encoding glutamate 1-semialdehyde aminotransferase confers gabaculine resistance when expressed in tobacco plastids. Plant Cell Rep 34(12):2127-2136. doi:10.1007/s00299-015-1856-z

Bendich AJ (1987) Why do chloroplasts and mitochondria contain so many copies of their genome? BioEssays 6:279-282. doi:10. 1002/bies.950060608

Birch-Machin I, Newell CA, Hibberd JM, Gray JC (2004) Accumulation of rotavirus VP6 protein in chloroplasts of transplastomic tobacco is limited by protein stability. Plant Biotechnol J 2:261-270. doi:10.1111/j.1467-7652.2004.00072.x

Bock R (2014) Genetic engineering of the chloroplast: novel tools and new applications. Curr Opin Biotechnol 26:7-13. doi:10.1016/j. copbio.2013.06.004

Bock R (2015) Engineering plastid genomes: methods, tools, and applications in basic research and biotechnology. Annu Rev Plant Biol 66:3.1-3.31

Bock R, Warzecha H (2010) Solar-powered factories for new vaccines and antibiotics. Trends Biotechnol 28:246-252. doi:10.1016/j.tibtech.2010.01.006

Buhot L, Horvath E, Medgyesy P, Lerbs-Mache S (2006) Hybrid transcription system for controlled plastid transgene expression. Plant J 46:700-707. doi:10.1111/j.1365-313X.2006.02718.x

Buntru M, Gartner S, Staib L, Kreuzaler F, Schlaich N (2013) Delivery of multiple transgenes to plant cells by an improved version of Multiround Gateway technology. Transgenic Res 22:153-167. doi:10.1007/s11248-012-9640-0

Caddick MX et al (1998) An ethanol inducible gene switch for plants used to manipulate carbon metabolism. Nat Biotechnol 16:177-180. doi:10.1038/nbt0298-177

Cahoon EB, Shanklin J, Ohlrogge JB (1992) Expression of a coriander desaturase results in petroselinic acid production in transgenic tobacco. Proc Natl Acad Sci USA 89:11184-11188

Capeding MR et al (2014) Clinical efficacy and safety of a novel tetravalent dengue vaccine in healthy children in Asia: a phase 3, randomised, observer-masked, placebo-controlled trial. Lancet 384:1358-1365. doi:10.1016/s0140-6736(14)61060-6

Cardoso SA, Paixao VF, Oliveira MD, Honda ER, Oliveira LL, da Silva CC, De Paula SO (2013) Dengue-1 envelope protein domain III produced in Pichia pastoris: potential use for serological diagnosis. Protein Expr Purif 92:9-13. doi:10.1016/ j.pep. 2013.08 .014

Chaturvedi UC, Nagar R (2008) Dengue and dengue haemorrhagic fever: Indian perspective. J Biosci 33:429-441

Clarke J, Daniell H (2011) Plastid biotechnology for crop production: present status and future perspectives. Plant Mol Biol 76:211-220. doi:10.1007/s11103-011-9767-z

Clarke JL, Zhang P (2013) Plant biotechnology for food security and bioeconomy. Plant Mol Biol 83:1-3. doi:10.1007/s11103-0130097-1

Clements DE et al (2010) Development of a recombinant tetravalent dengue virus vaccine: immunogenicity and efficacy studies in mice and monkeys. Vaccine 28:2705-2715. doi:10.1016/j. vaccine.2010.01.022

Daniell H (1997) Transformation and foreign gene expression in plants mediated by microprojectile bombardment. In: Tuan RS (ed) Recombinant gene expression protocols. Methods in molecular biology, vol 62. Humana Press Inc, NJ, pp 463-489. doi:10.1385/0-89603-480-1:463

Daniell H (2006) Henry Daniell: chloroplast genetic engineering. Biotechnol J 1:31-33. doi:10.1002/biot.200690011

Dasgupta S, Collins GB, Hunt AG (1998) Co-ordinated expression of multiple enzymes in different subcellular compartments in plants. Plant J 16:107-116. doi:10.1046/j.1365-313x.1998.00255.x

De Marchis F, Pompa A, Bellucci M (2012) Plastid proteostasis and heterologous protein accumulation in transplastomic plants. Plant Physiol 160:571-581. doi:10.1104/pp.112.203778

De Marchis F, Bellucci M, Pompa A (2016) Phaseolin expression in tobacco chloroplast reveals an autoregulatory mechanism in heterologous protein translation. Plant Biotechnol J 14(2):603-614. doi:10.1111/pbi.12405

Dubin M, Bowler C, Benvenuto G (2008) A modified Gateway cloning strategy for overexpressing tagged proteins in plants. Plant Methods 4:1746-4811

Dubin MJ, Bowler C, Benvenuto G (2010) Overexpressing tagged proteins in plants using a modified gateway cloning strategy. Cold Spring Harbor Protoc. doi:10.1101/pdb.prot5401

Earley KW, Haag JR, Pontes O, Opper K, Juehne T, Song K, Pikaard CS (2006) Gateway-compatible vectors for plant functional genomics and proteomics. Plant J 45:616-629. doi:10.1111/j. 1365-313X.2005.02617.x

Eberhard S, Drapier D, Wollman FA (2002) Searching limiting steps in the expression of chloroplast-encoded proteins: relations between gene copy number, transcription, transcript abundance and translation rate in the chloroplast of Chlamydomonas reinhardtii. Plant J 31:149-160

Emadpour M, Karcher D, Bock R (2015) Boosting riboswitch efficiency by RNA amplification. Nucleic Acids Res 43:e66. doi:10.1093/nar/gkv165

Etemad B, Batra G, Raut R, Dahiya S, Khanam S, Swaminathan S, Khanna N (2008) An envelope domain III-based chimeric antigen produced in Pichia pastoris elicits neutralizing antibodies against all four dengue virus serotypes. Am J Trop Med Hyg 79:353-363

Fischer R, Schillberg S, Hellwig S, Twyman RM, Drossard J (2012) GMP issues for recombinant plant-derived pharmaceutical proteins. Biotechnol Adv 30:434-439. doi:10.1016/j.biotechadv.2011.08. 007

Fischer R, Schillberg S, Buyel JF, Twyman RM (2013) Commercial aspects of pharmaceutical protein production in plants. Curr Pharm Des 19:5471-5477

Fischer R, Vasilev N, Twyman RM, Schillberg S (2015) High-value products from plants: the challenges of process optimization. Curr Opin Biotechnol 32:156-162. doi:10.1016/j.copbio.2014. 12.018 
Ghosh A, Dar L (2015) Dengue vaccines: challenges, development, current status and prospects Indian. J Med Microbiol 33:3-15

Gottschamel J, Waheed MT, Clarke JL, Lossl AG (2013) A novel chloroplast transformation vector compatible with the Gateway $(\mathrm{R}))$ recombination cloning technology. Transgenic Res 22:1273-1278. doi:10.1007/s11248-013-9726-3

Gubler DJ (2012) The economic burden of dengue. Am J Trop Med Hyg 86(5):743-744. doi:10.4269/ajtmh.2012.12-0157

Guirakhoo F et al (2001) Construction, safety, and immunogenicity in nonhuman primates of a chimeric yellow fever-dengue virus tetravalent vaccine. J Virol 75:7290-7304. doi:10.1128/jvi.75. 16.7290-7304.2001

Guy B, Barrere B, Malinowski C, Saville M, Teyssou R, Lang J (2011) From research to phase III: preclinical, industrial and clinical development of the Sanofi Pasteur tetravalent dengue vaccine. Vaccine 29:7229-7241. doi:10.1016/j.vaccine.2011.06. 094

Guzman MG, Hermida L, Bernardo L, Ramirez R, Guillen G (2010) Domain III of the envelope protein as a dengue vaccine target. Expert Rev Vaccines 9:137-147. doi:10.1586/erv.09.139

Hadinegoro SR et al (2015) Efficacy and long-term safety of a dengue vaccine in regions of endemic disease. N Engl J Med. doi:10. 1056/NEJMoa1506223

Hennig A, Bonfig K, Roitsch T, Warzecha H (2007) Expression of the recombinant bacterial outer surface protein $\mathrm{A}$ in tobacco chloroplasts leads to thylakoid localization and loss of photosynthesis. Febs J 274:5749-5758. doi:10.1111/j.1742-4658. 2007.06095.x

Herz S, Füß1 M, Steiger S, Koop H-U (2005) Development of novel types of plastid transformation vectors and evaluation of factors controlling expression. Transgenic Res 14:969-982. doi:10. 1007/s11248-005-2542-7

Hombach J et al (2005) Review on flavivirus vaccine development. In: Proceedings of a meeting jointly organised by the World Health Organization and the Thai Ministry of Public Health, 26-27 April 2004, Bangkok, Thailand. Vaccine 23:2689-2695

Ivy J, Nakano E, Clements D (2000) Subunit immunogenic composition against dengue infection

Jaiswal S, Khanna N, Swaminathan S (2004) High-level expression and one-step purification of recombinant dengue virus type 2 envelope domain III protein in Escherichia coli. Protein Expr Purif 33:80-91. doi:10.1016/j.pep.2003.09.009

Kahlau S, Bock R (2008) Plastid transcriptomics and translatomics of tomato fruit development and chloroplast-to-chromoplast differentiation: chromoplast gene expression largely serves the production of a single protein. Plant Cell 20:856-874. doi:10. 1105/tpc.107.055202

Kanagaraj AP, Verma D, Daniell H (2011) Expression of dengue-3 premembrane and envelope polyprotein in lettuce chloroplasts. Plant Mol Biol 76:323-333. doi:10.1007/s11103-011-9766-0

Karimi M, Inzé D, Depicker A (2002) GATEWAY ${ }^{\mathrm{TM}}$ vectors for Agrobacterium-mediated planttransformation. Trends Plant Sci 7:193-195

Karimi M, Depicker A, Hilson P (2007) Recombinational cloning with plant gateway vectors. Plant Physiol 145:1144-1154

Karimi M, Inze D, Van Lijsebettens M, Hilson P (2013) Gateway vectors for transformation of cereals. Trends Plant Sci 18:1-4. doi:10.1016/j.tplants.2012.10.001

Katzen F (2007) Gateway ${ }^{\circledR}$ recombinational cloning: a biological operating system. Expert Opin Drug Discov 2:571-589. doi:10. 1517/17460441.2.4.571

Khanam S, Etemad B, Khanna N, Swaminathan S (2006) Induction of neutralizing antibodies specific to dengue virus serotypes 2 and 4 by bivalent antigen composed of linked envelop domains III of these two serotypes. Am J Trop Med Hyg 74:266-277
Kim J, Klein PG, Mullet JE (1994) Synthesis and turnover of photosystem II reaction center protein D1. Ribosome pausing increases during chloroplast development. J Biol Chem 269: 17918-17923

Kim TG, Kim MY, Huy NX, Kim SH, Yang MS (2013) M celltargeting ligand and consensus dengue virus envelope protein domain III fusion protein production in transgenic rice calli. Mol Biotechnol 54(3):880-887. doi:10.1007/s12033-012-9637-1

Koop H-U, Herz S, Golds T, Nickelsen J (2007) The genetic transformation of plastids. In: Bock R (ed) Cell and molecular biology of plastids, vol 19. Topics in current genetics. Springer, Heidelberg, pp 457-510. doi:10.1007/4735_2007_0225

Kuhn RJ et al (2002) Structure of dengue virus: implications for flavivirus organization, maturation, and fusion. Cell 108:717-725

Kuroda H, Maliga P (2001) Complementarity of the 16S rRNA penultimate stem with sequences downstream of the AUG destabilizes the plastid mRNAs. Nucleic Acids Res 29:970-975

Lössl AG, Waheed MT (2011) Chloroplast-derived vaccines against human diseases: achievements, challenges and scopes. Plant Biotechnol J 9:527-539. doi:10.1111/j.1467-7652.2011.00615.x

Lössl A, Eibl C, Harloff HJ, Jung C, Koop HU (2003) Polyester synthesis in transplastomic tobacco (Nicotiana tabacum L.): significant contents of polyhydroxybutyrate are associated with growth reduction. Plant Cell Rep 21:891-899. doi:10.1007/ s00299-003-0610-0

Lössl A, Bohmert K, Harloff H, Eibl C, Mühlbauer S, Koop H-U (2005) Inducible trans-activation of plastid transgenes: expression of the $R$. eutropha phb operon in transplastomic tobacco. Plant Cell Physiol 46:1462-1471

Lu Y, Rijzaani H, Karcher D, Ruf S, Bock R (2013) Efficient metabolic pathway engineering in transgenic tobacco and tomato plastids with synthetic multigene operons. Proc Natl Acad Sci USA 110:E623-E632. doi:10.1073/pnas.1216898110

Lyska D, Engelmann K, Meierhoff K, Westhoff P (2013) pAUL: a gateway-based vector system for adaptive expression and flexible tagging of proteins in Arabidopsis. PLoS ONE. doi:10. 1371/journal.pone.0053787

Ma S, Wang A (2012) Molecular farming: an Overview. In: Wang A, Ma S (eds) Molecular farming in plants: recent advances and future prospects. Springer, Netherlands, pp 1-20

Magee AM, Coyne S, Murphy D, Horvath EM, Medgyesy P, Kavanagh TA (2004) T7 RNA polymerase-directed expression of an antibody fragment transgene in plastids causes a semilethal pale-green seedling phenotype. Transgenic Res 13: 325-337

Maliga P, Bock R (2011) Plastid biotechnology: food, fuel, and medicine for the 21st century. Plant Physiol 155:1501-1510

Martinez CA, Topal E, Giulietti AM, Talou JR, Mason H (2010) Exploring different strategies to express dengue virus envelope protein in a plant system. Biotechnol Lett 32:867-875. doi:10. 1007/s10529-010-0236-6

McBride KE, Schaaf DJ, Daley M, Stalker DM (1994) Controlled expression of plastid transgenes in plants based on a nuclear DNA-encoded and plastid-targeted T7 RNA polymerase. Proc Natl Acad Sci USA 91:7301-7305

McDonald W, Powell T, Price A, Becker R (2009) Compositions of dengue viral proteins and methods of use

Melnik S, Stöger E (2013) Green factories for biopharmaceuticals. Curr Med Chem 20:1038-1046

Modis Y, Ogata S, Clements D, Harrison SC (2003) A ligand-binding pocket in the dengue virus envelope glycoprotein. Proc Natl Acad Sci 100:6986-6991

Modis Y, Ogata S, Clements D, Harrison SC (2004) Structure of the dengue virus envelope protein after membrane fusion. Nature 427:313-319. doi:10.1038/nature02165 
Mühlbauer SK, Koop H-U (2005) External control of transgene expression in tobacco plastids using the bacterial lac repressor. Plant J 43:941-946. doi:10.1111/j.1365-313X.2005.02495.x

Mukhopadhyay S, Kuhn RJ, Rossmann MG (2005) A structural perspective of the flavivirus life cycle. Nat Rev Microbiol 3:13-22. doi:10.1038/nrmicro1067

Murashige T, Skoog F (1962) A revised medium for rapid growth and bio-assays with tobacco tissue cultures. Physiol Plant 15(3):473-497

Murray M, Thompson W (1980) Rapid isolation of high molecular weight plant DNA. Nucleic Acids Res 8:4321-4326. doi:10. 1093/nar/8.19.4321

Nakakura M, Hibi Y, Okamoto T, Sugiura M (2016) Cooperation between the chloroplast psbA $5^{\prime}$-untranslated region and coding region is important for translational initiation: the chloroplast translation machinery cannot read a human viral gene coding region. The Plant J 85:772-780. doi:10.1111/tpj.13150

Nawrath C, Poirier Y, Somerville C (1994) Targeting of the polyhydroxybutyrate biosynthetic pathway to the plastids of Arabidopsis thaliana results in high levels of polymer accumulation. Proc Natl Acad Sci 91:12760-12764

New JS, Westerveld D, Daniell H (2012) Chloroplast-derived therapeutic and prophylactic vaccines. In: Wang A, Ma S (eds) Molecular farming in plants: recent advances and future prospects. Springer, Netherlands, pp 69-87

Nguyen NL, So KK, Kim JM, Kim SH, Jang YS, Yang MS, Kim DH (2015) Expression and characterization of an M cell-specific ligand-fused dengue virus tetravalent epitope using Saccharomyces cerevisiae. J Biosci Bioeng 119:19-27

Oey M, Lohse M, Kreikemeyer B, Bock R (2009a) Exhaustion of the chloroplast protein synthesis capacity by massive expression of a highly stable protein antibiotic. Plant J 57:436-445. doi:10.1111/ j.1365-313X.2008.03702.x

Oey M, Lohse M, Scharff LB, Kreikemeyer B, Bock R (2009b) Plastid production of protein antibiotics against pneumonia via a new strategy for high-level expression of antimicrobial proteins. Proc Natl Acad Sci USA 106:6579-6584. doi:10.1073/pnas. 0813146106

Petersen K, Bock R (2011) High-level expression of a suite of thermostable cell wall-degrading enzymes from the chloroplast genome. Plant Mol Biol 76:311-321. doi:10.1007/s11103-0119742-8

Rappsilber J, Ishihama Y, Mann M (2003) Stop and go extraction tips for matrix-assisted laser desorption/ionization, nanoelectrospray, and LC/MS sample pretreatment in proteomics. Anal Chem 75:663-670

Roslan HA et al (2001) Characterization of the ethanol-inducible alc gene-expression system in Arabidopsis thaliana. Plant $\mathrm{J}$ 28:225-235. doi:10.1046/j.1365-313X.2001.01146.x

Ruf S, Hermann M, Berger IJ, Carrer H, Bock R (2001) Stable genetic transformation of tomato plastids and expression of a foreign protein in fruit. Nat Biotechnol 19:870-875. doi:10.1038/ nbt0901-870

Ruf S, Karcher D, Bock R (2007) Determining the transgene containment level provided by chloroplast transformation. Proc Natl Acad Sci USA 104:6998-7002. doi:10.1073/pnas. 0700008104

Saejung W et al (2007) Production of dengue 2 envelope domain III in plant using TMV-based vector system. Vaccine 25:6646-6654. doi:10.1016/j.vaccine.2007.06.029

Salter MG, Paine JA, Riddell KV, Jepson I, Greenland AJ, Caddick MX, Tomsett AB (1998) Characterisation of the ethanolinducible-alc-gene expression system for transgenic plants. Plant J 16:127-132. doi:10.1046/j.1365-313x.1998.00281.x

Scotti N, Cardi T (2014) Transgene-induced pleiotropic effects in transplastomic plants. Biotechnol Lett 36:229-239. doi:10.1007/ s10529-013-1356-6
Scotti N, Bellucci M, Cardi T (2013) The chloroplasts as platform for recombinant proteins production. In: Translation in mitochondria and other organelles. Springer, Heidelberg, pp 225-262. doi:10. 1007/978-3-642-39426-3_10

Scotti N et al (2015) The HIV-1 Pr55gag polyprotein binds to plastidial membranes and leads to severe impairment of chloroplast biogenesis and seedling lethality in transplastomic tobacco plants. Transgenic Res 24:319-331. doi:10.1007/s11248-0149845-5

Shevchenko A, Tomas H, Havlis J, Olsen JV, Mann M (2006) In-gel digestion for mass spectrometric characterization of proteins and proteomes. Nat Protoc 1:2856-2860. doi:10.1038/nprot.2006. 468

Simmons M, Hayes C, Porter K (1999) Recombinant dengue virus envelop protein/maltose-binding protein antigens and subunit vaccine compositions containing said antigens

Srivastava A, Putnak J, Hoke C, Warren R (2000) Recombinant vaccine made in E.coli against dengue virus

Staub JM, Maliga P (1993) Accumulation of D1 polypeptide in tobacco plastids is regulated via the untranslated region of the psbA mRNA. EMBO J 12(2):601-606

Svab Z, Maliga P (1993) High-frequency plastid transformation in tobacco by selection for a chimeric aadA gene. Proc Natl Acad Sci USA 90:913-917

Svab Z, Maliga P (2007) Exceptional transmission of plastids and mitochondria from the transplastomic pollen parent and its impact on transgene containment. Proc Natl Acad Sci USA 104:7003-7008. doi:10.1073/pnas.0700063104

Tabor S, Richardson CC (1985) A bacteriophage T7 RNA polymerase/promoter system for controlled exclusive expression of specific genes. Proc Natl Acad Sci 82:1074-1078

Thomas SJ (2015) Preventing dengue-is the possibility now a reality? N Engl J Med 372:172-173. doi:10.1056/NEJMe1413146

Tissot G, Canard H, Nadai M, Martone A, Botterman J, Dubald M (2008) Translocation of aprotinin, a therapeutic protease inhibitor, into the thylakoid lumen of genetically engineered tobacco chloroplasts. Plant Biotechnol J 6:309-320. doi:10.1111/ j.1467-7652.2008.00321.x

Tregoning JS et al (2003) Expression of tetanus toxin fragment $\mathrm{C}$ in tobacco chloroplasts. Nucleic Acids Res 31:1174-1179

Tripathi NK, Babu JP, Shrivastva A, Parida M, Jana AM, Rao PV (2008) Production and characterization of recombinant dengue virus type 4 envelope domain III protein. J Biotechnol 134:278-286. doi:10.1016/j.jbiotec.2008.02.001

Tripathi NK, Shrivastava A, Biswal KC, Rao PV (2011) Recombinant dengue virus type 3 envelope domain III protein from Escherichia coli. Biotechnol J 6:604-608. doi:10.1002/biot. 201000399

Tungsuchat T, Kuroda H, Narangajavana J, Maliga P (2006) Gene activation in plastids by the CRE site-specific recombinase. Plant Mol Biol 61:711-718. doi:10.1007/s11103-006-0044-5

Tuse D, Tu T, McDonald KA (2014) Manufacturing economics of plant-made biologics: case studies in therapeutic and industrial enzymes. Biomed Res Int 2014:256135. doi:10.1155/2014/ 256135

Verhounig A, Karcher D, Bock R (2010) Inducible gene expression from the plastid genome by a synthetic riboswitch. Proc Natl Acad Sci 107:6204-6209

Villar L et al (2015) Efficacy of a tetravalent dengue vaccine in children in Latin America. N Engl J Med 372(2):113-123. doi:10.1056/NEJMoa1411037

Waheed MT et al (2011) Plastid expression of a double-pentameric vaccine candidate containing human papillomavirus-16 L1 antigen fused with LTB as adjuvant: transplastomic plants show pleiotropic phenotypes. Plant Biotechnol J 9:651-660. doi:10. 1111/j.1467-7652.2011.00612.x 
Wani S, Sah S, Sági L, Solymosi K (2015) Transplastomic plants for innovations in agriculture. A review agronomy for sustainable development:1-40 doi:10.1007/s13593-015-0310-5

Weaver SC, Vasilakis N (2009) Molecular evolution of dengue viruses: contributions of phylogenetics to understanding the history and epidemiology of the preeminent arboviral disease infection. Genet Evolut 9:523-540. doi:10.1016/j.meegid.2009. 02.003

WHO (2015) Factsheet on dengue and dengue haemorrhagic fever. World Health Organization. http://www.who.int/mediacentre/ factsheets/fs117/en/

Ye GN, Hajdukiewicz PTJ, Broyles D, Rodriguez D, Xu CW, Nehra N, Staub JM (2001) Plastid-expressed 5-enolpyruvylshikimate3-phosphate synthase genes provide high level glyphosate tolerance in tobacco. Plant J 25:261-270. doi:10.1046/j.1365313x.2001.00958.x

Yusibov V, Streatfield SJ, Kushnir N (2011) Clinical development of plant-produced recombinant pharmaceuticals: vaccines, antibodies and beyond. Hum Vaccinces 7:313-321

Zhao $\mathrm{H}$ et al (2014) Induction of neutralizing antibodies against four serotypes of dengue viruses by MixBiEDIII, a tetravalent dengue vaccine. PLoS ONE 9:e86573. doi:10.1371/journal.pone. 0086573

Zhou $F$ et al (2008) High-level expression of human immunodeficiency virus antigens from the tobacco and tomato plastid genomes. Plant Biotechnol J 6:897-913. doi:10.1111/j.14677652.2008.00356.x 